\title{
Influence of carburization on the structure and properties of functional diffusion coatings based on titanium carbide on TiC-WC-Co and WC-Co alloys
}

\author{
A. G. Sokolov, E. E. Bobylyov ${ }^{\dagger}$, R. L. Plomod'ialo \\ †ebobylev@mail.ru \\ Kuban State Technological University, 2 Moskovskaya St., Krasnodar, 350000, Russia
}

The technology of applying diffusion titanium coatings from the medium of low-melting liquid-metal melts to hard alloys of the TiC-WC-Co and WC-Co types is described. It is shown that in the case of diffusion saturation of the surface layers of a hard alloy tool of the TiC-WC-Co and WC-Co types with titanium from the Pb-Bi-Li-Ti melt, preliminary carburization is an obligatory stage in the process of coating formation, and allows avoiding the formation of a decarburized zone under the diffusion layer. The effect of preliminary carburization on the phase composition of the coated hard alloy is shown. As a result of the phase analysis, it was revealed that the surface layer contains such phases as $\mathrm{WC}, \mathrm{TiC}, \mathrm{Co}_{2} \mathrm{C}, \mathrm{Co}-\mathrm{C}$. In this case, titanium carbide $\mathrm{TiC}$ is formed due to the destruction of cobalt carbide upon further diffusion saturation with titanium. In the absence of carburization, the formation of a decarbidized layer was revealed, which differs from the coating and the base in lower microhardness, the drop in microhardness is about $1000 \mathrm{MPa}$. After carburization, there was a slight increase in the hardness of the coated parts from 89 to 91 HRA. Characteristics such as the microhardness of the carburization zone and its length depend on the temperature and duration of the preliminary carburization, as well as on the elemental composition of the material to be coated. Carburization was carried out in the temperature range from $950^{\circ} \mathrm{C}$ to $1150^{\circ} \mathrm{C}$ from 30 to 120 minutes. After saturation with carbon, the thickness of the carburization zone was from 2 to $25 \mu \mathrm{m}$, the microhardness from 16700 to $17150 \mathrm{MPa}$ for the WC-Co alloy and from 18750 to $19200 \mathrm{MPa}$ for the TiC-WC-Co alloy. The hardness of the layer under the coating ranged from 27000 to $28500 \mathrm{MPa}$ for the TiC-WC-Co alloy and from 19300 to $23500 \mathrm{MPa}$ for the WC-Co-type alloy.

Keywords: diffusion, hard alloy, coating, carburization.

УДК: 621.793 .5

\section{Влияние цементации на структуру и свойства функциональных диффузионных покрытий на базе карбида титана на твердых сплавах типа ТК и ВК}

\author{
Соколов А. Г., Бобылёв Э. Э. ${ }^{\dagger}$, Пломодьяло Р. Л.
}

ФБГОУ ВО Кубанский государственный технологический университет, ул. Московская, 2, Краснодар, 350000, Россия

Описана технология нанесения диффузионных титановых покрытий из среды легкоплавких жидкометаллических
расплавов на твердые сплавы типа ТК и ВК. При диффузионном насыщении поверхностных слоев твердосплавного
инструмента типа ТК и ВК титаном из расплава Pb-Bi-Li-Ti, предварительная цементация является обязательным
этапом в процессе формирования покрытия, и позволяет избежать образования обезуглероженной зоны
под диффузионным слоем. Выявлено влияние предварительной цементации на фазовый состав покрываемого
твердого сплава. В результате фазового анализа установлено, что поверхностный слой содержит такие фазы, как WC,
ТіС, Со С, Со-С. При этом карбид титана ТіС образуется вследствие деструкции карбида кобальта при дальнейшем
диффузионном насыщении титаном. При отсутствии цементации происходит формирование декарбидизированного
слоя, отличающийся от покрытия и основы меньшей микротвердостью, падение микротвердости составляет порядка
1000 МПа. После цементации наблюдалось незначительное увеличение твердости покрытых изделий с 89 до 91 НRA.
Такие характеристики, как микротвердость зоны цементации и её протяженность зависят от температуры 
и длительности предварительной цементации, а также, от элементного состава покрываемого материала. Цементация проводилась в диапазоне температур от $950^{\circ} \mathrm{C}$ до $1150^{\circ} \mathrm{C}$ от 30 до 120 минут. После насыщения углеродом толщина цементованой зоны составляла от 2 до 25 мкм, микротвердость от 16700 до 17150 МПа для сплавов ВК и от 18750 до 19200 МПа для сплава ТК. Твердость слоя под покрытием составила от 27000 до 28500 МПа для сплава ТК и от 19300 до 23500 МПа для сплава типа ВК.

Ключевые слова: диффузия, твердый сплав, покрытие, насыщение углеродом.

\section{1. Введение}

Нанесение функциональных покрытий на базе карбидов на режущие инструменты в настоящее время - один из эффективных способов увеличения их износостойкости. При этом, достаточно распространенными инструментальными материалами при обработке резинием выступают вольфрамокобальтовые (ВК8) и титановольфрамокобальтовые (Т15К6) твердые сплавы. Современным, и наиболее часто используемым способом управления эксплуатационными свойствами данных материалов является формирование на их поверхности функциональных покрытий на базе карбидов титана, тантала, хрома, вольфрама, ниобия [1]. При этом покрытия на основе карбидов титана одни из наиболее распространенных благодаря их высокой микротвердости, износостойкости и распространенности титана. При этом, одной из перспективных технологий нанесения покрытий представляется диффузионное титанирование в среде легкоплавких жидкометаллических расплавов [1-4].

Для формирования покрытий из карбида титана могут использоваться технологии CVD, PVD, XTO. Диффузионная металлизация из среды легкоплавких жидкометаллических расплавов выступает как одна из перспективных технологий. Технология диффузионной металлизации в среде легкоплавких жидкометаллических растворов обладает мировой новизной и в настоящее время применяется исключительно в РФ. Преимущества данной технологии по сравнению с PVD и CVD: высокая совместимость покрытия с покрываемым материалом, возможность покрывать изделия любой формы, простота оборудования, возможность получения многокомпонентных покрытий [1-7].

Нанесение износостойких диффузионных титановых покрытий на твердые сплавы в среде легкоплавких жидкометаллических растворов существенно влияет на микроструктуру и фазовый состав их поверхностных слоев, и как следствие - на твердость и износостойсть этих сплавов в целом [2-4].

Однако при диффузионном насыщении твердых сплавов карбидообразующими элементами, в частности титаном, происходит обеднение поверхностных слоев покрываемого изделия углеродом вследствие диффузии углерода к титану [5,6]. Данный эффект является нежелательным и приводит к образованию под покрытием обезуглероженной зоны, которая характеризуется пониженной твердостью как по сравнению с покрытием, так и по сравнению с материалом-основой. Падение микротвердости находится в пределах $1000-1500 \mathrm{MПа}[7,8]$.

Наличие обезуглероженного слоя при нанесении титановых покрытий так же снижает предел прочности покрытого материала на 20 - 30\% [9]. При этом, влияние, оказываемое обезуглероженным слоем на статические характеристики покрытого материала и на его макротвердость, зависит от глубины обезуглероженного слоя и степени его обезуглероживания. Устранить образование обезуглероженного слоя можно путем включения в технологический цикл стадии предварительной высокотемпературной цементации, обеспечивающей обогащение поверхностных слоев покрываемых изделий углеродом, за счет которого впоследствии формируется покрытие на базе карбида титана.

Как показали проведенные исследования степень, обезуглероживания слоя под покрытием зависит от соотношения режимов предварительной высокотемпературной цементации, режимов нанесения покрытия и состава покрываемого материала. Чем больше толщина обезуглероженного слоя и степень его обезуглероживания, тем ниже твердость материала и его прочностные характеристики.

Цель данной работы - изучение влияния предварительной цементации на структуру и свойства твердых сплавов, а также на свойства диффузионных титановых покрытий, формирующихся путем их диффузионного легирования в среде легкоплавких жидкометаллических растворов.

\section{2. Методика}

Диффузионные покрытия наносились на исходно непокрытые образцы из твердых сплавов ВК8 (WC92\%-Co8\%) и Т15K6 (TiC15\%-WC79\%-Co6\%), подготовленные по ГОСТ 20019-74, размерами $35 \times 5 \times 5$ мм.

В качестве легкоплавкого расплава, осуществляющего доставку элемента к поверхности покрываемого изделия, использовался расплав эвтектического состава свинец-висмут-литий, в который в заданном количестве вводился титан.

Перед процессом диффузионного насыщения изделия подвергались кратковременной высокотемпературной цементации в вакууме. Цементация проводилась с применением технологии вакуумной цементации в среде пропан-бутановой смеси в вакуумной печи BMI BMICRO. Температура цементации варьировалась от $950^{\circ} \mathrm{C}$ до $1150^{\circ} \mathrm{C}$, время от 30 до 120 минут при 1925 Па.

Твердость пластин проверялась по методу Роквелла и методу микро-Виккерса. Твердость по Роквеллу определялась на твердомере ТК-2М по стандартной методике, по шкале «А». Металлографические исследования проводились на микрошлифах, подготовленных по стандартной методике. Исследования по определению микротвердости проводились на микротвердомере DuraScan 80. Производилось 3 серии измерений, после 
чего строился график изменения микротвердости. Измерение микротвердости поверхностных слоев после цементации проводилось при нагрузке $0.2 \mathrm{H}$.

Состав поверхностного слоя и переходной зоны исследовался методом рентгеноспектрального микроанализа. При этом использовался растровый электронный микроскоп JEOL JSM-7500F и спектрометр INCA $\mathrm{x}$-sight oxford instruments.

Фазовый состав покрытий определялся на многофункциональном рентгеновском дифрактометре ДРОН-7М. Съемка дифрактограмм велась на излучении $\mathrm{CuK}_{\alpha}$ при напряжении 30 кВ и силе тока 20 мА. Для идентификации фаз использовалась база данных ICDD PDF-2.

\section{3. Результаты и обсуждение}

При цементации твердого сплава элементом, который можно насытить углеродом, является кобальт. При этом, согласно диаграмме состояния (Со-С) [10], при кратковременном насыщении в поверхностных слоях твердого сплава образуется твердый раствор углерода в кобальте, с дальнейшим образованием карбида кобальта $\mathrm{Co}_{2} \mathrm{C}$.

Для изучения структуры поверхностного слоя после цементации проведен рентгенофазовый анализ. Как видно из Рис. 1-3, при цементации образуются новая фаза - карбид кобальта Со $\mathrm{C}_{2}$

Микроструктурный анализ показал наличие карбида вольфрама WC (светлые включения) и ТiC (серый фон), изначально присутствующие в твердом сплаве. Также обнаружены включения карбида кобальта $\mathrm{Co}_{2} \mathrm{C}$ (темный фон) и небольшие включения не прореагировавших Со и С.

В результате фазового анализа было установлено, что поверхностный слой содержит такие фазы, как WC, $\mathrm{TiC}, \mathrm{Co}_{2} \mathrm{C}, \mathrm{Co}-\mathrm{C}$ (Рис. 3).

Таким образом, благодаря предварительной цементации, при последующем титанировании формирование покрытия происходит за счет углерода, полученного при цементации, а не за счет углерода материала-основы.

Выбор режима предварительной цементации существенно влияет на твердость, и, как следствие, на стойкость режущего твердосплавного инструмента, имеющего титановое покрытие [2,3]. Было установлено, что основным параметром, влияющим на количество углерода, получаемого при цементации, является температура процесса. При повышении температуры цементации возрастает растворимость углерода в кобальтовой связке, а также возрастает концентрация углерода в виде карбида кобальта $\mathrm{Co}_{2} \mathrm{C}$ в поверхностном слое.

Более информативной, с точки зрения влияния температуры цементации на свойства науглероженных поверхностных слоев твердых сплавов, является микротвердость (Рис. 4).

Как следует из анализа зависимости микротвердости поверхностных слоев твердых сплавов Т15К6 и ВК8 на поверхностную микротвердость, значительное влияние оказывает температура цементации. Так с повышением температуры цементации с $950^{\circ} \mathrm{C}$ до $1150^{\circ} \mathrm{C}$ поверхностная микротвердость сплава Т15К6 возрас-

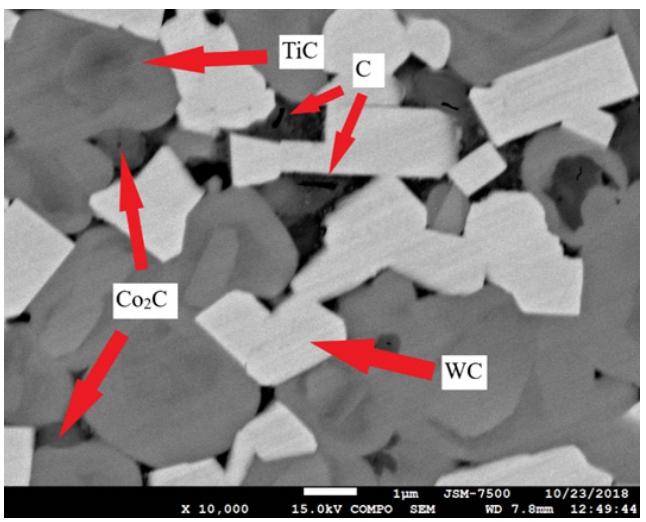

Pис. 1. Топография поверхности сплава Т15К6 после цементации при температуре $1000^{\circ} \mathrm{C}$ в течение 30 минут.

Fig. 1. Topography of TiC15\%-WC79\%-Co6\% alloy surface after carburization at $1000^{\circ} \mathrm{C}$ during 30 minutes.

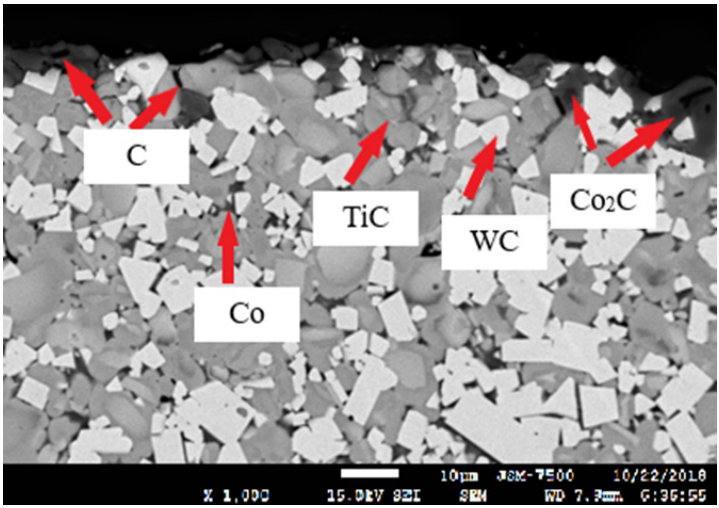

Рис. 2. Микроструктура сплава Т15К6 после цементации при температуре $1000^{\circ} \mathrm{C}$ в течение 30 минут.

Fig. 2. Microstructure of TiC15\%-WC79\%-Co6\% alloy surface after carburization at $1000^{\circ} \mathrm{C}$ during 30 minutes.
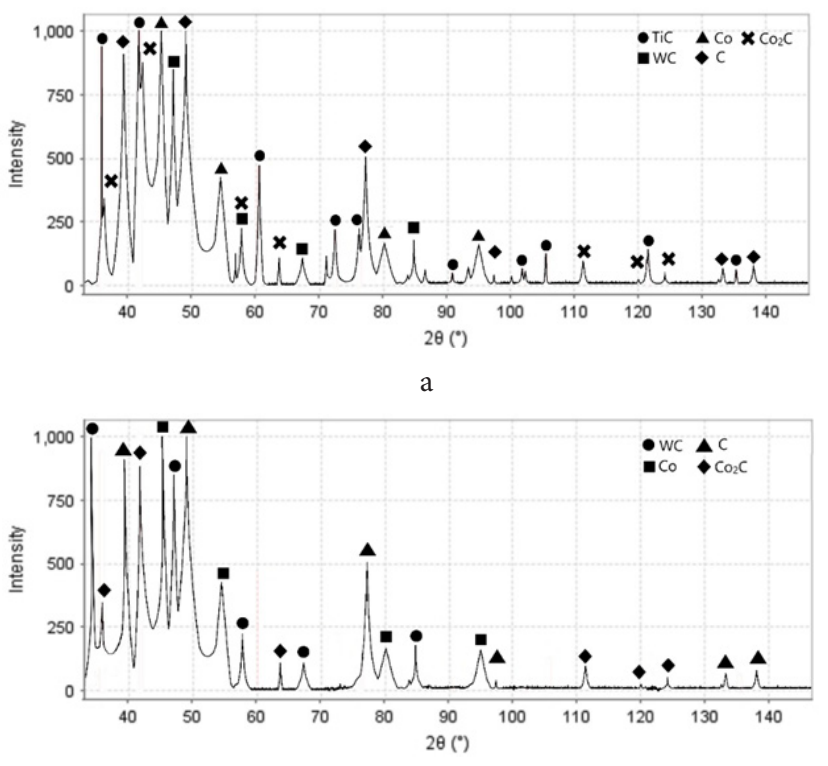

b

Рис. 3. Дифрактограммы поверхности твердых сплавов после цементации в вакууме: Т15К6 (a), ВК8 (b).

Fig. 3. Diffracktograms of hard alloys surface after vacuum carburization: TiC15\%-WC79\%-Co6\% (a), WC92\%-Co8\% (b). 


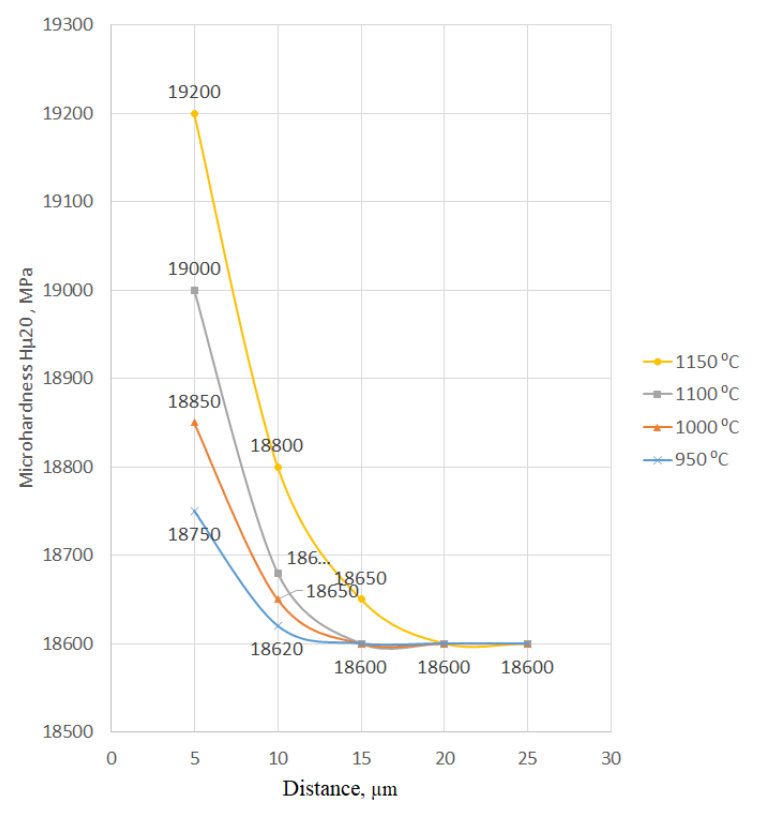

a

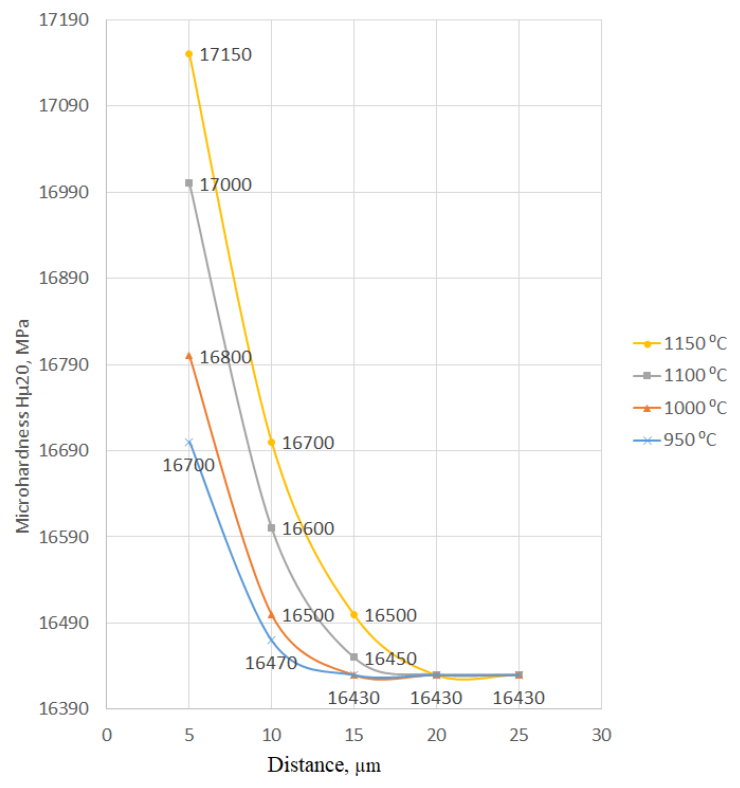

b

Pис. 4. (Color online) Влияние температуры предварительной цементации на микротвердость поверхностных слоев твердосплавных пластин: Т15К6 (a); ВК8 (b).

Fig. 4. (Color online) Temperature influence of previous carburization to surface layers microhardness of carbide-tipped tool: TiC15\%-WC79\%-Co6\% (a), WC92\%-Co8\% (b).

тает с 18750 до 19200 МПа. Аналогичное повышение поверхностной твердости наблюдается после цементации сплава ВК8. В данном случае повышение температуры цементации с $950^{\circ} \mathrm{C}$ до $1150^{\circ} \mathrm{C}$ поверхностная микротвердость сплава ВК8 возрастает с 16700 до 17150 МПа.

Также было установлено, что кроме изменения твердости режимы цементации оказывают влияние на глубину цементованного слоя (Рис. 5), и при этом глубина цементации не зависит от элементного состава твердого сплава.

В исследуемом диапазоне времени выдержки, зависимость глубины цементации от времени процесса имеет практически линейный характер. С увеличением времени цементации увеличивается толщина цементованого слоя. Максимальная глубина цементации была получена при $1150^{\circ} \mathrm{C}$ в течение 120 минут и составила 25 мкм. Однако, как показали исследования, повышение температур более $1100^{\circ} \mathrm{C}$ нецелесообразно, т.к. при дальнейшем диффузионном насыщении титаном возрастает количество карбидов и покрытие становится хрупким (Рис. 5). Исследования показали, что глубина цементации больше 15 мкм также нецелесообразна по причине повышения хрупкости слоя под покрытием, содержащем повышенную концентрацию углерода.

При увеличении температуры цементации увеличивается твердость инструмента. При этом температура мало влияет на макротвердость твердосплавного материала после цементации, что можно объяснить продавливанием цементованного слоя. Так, при увеличении температуры цементации от $950^{\circ} \mathrm{C}$ до $1150^{\circ} \mathrm{C}$ твердость сплава Т15К6 остается на уровне 90...91 HRA.

Таким образом, исследования процесса цементации показали, что после ее проведения в поверхностных слоях твердых сплавов, помимо насыщения их углеродом,

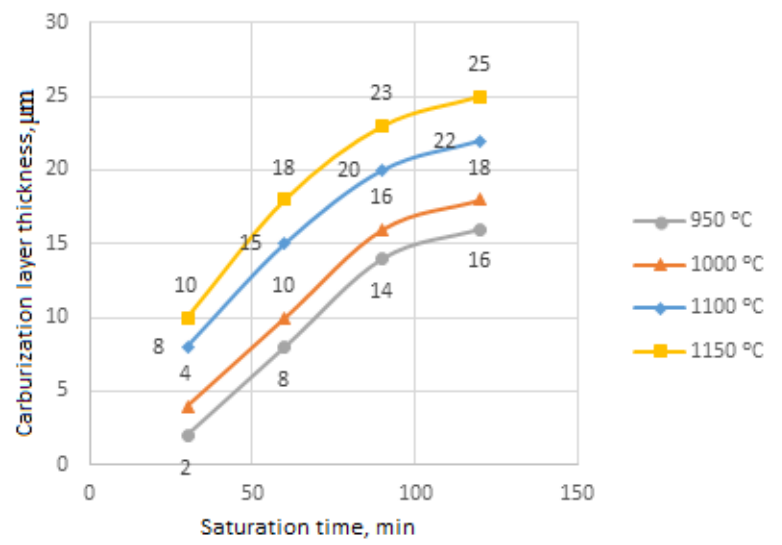

Pис. 5. (Color online) Зависимость глубины цементации от длительности процесса.

Fig. 5. (Color online) Depending of carburization depth to saturation time.

происходят значительные структурнофазовые изменения, и, как следствие, изменения их механических свойств. На эти изменения существенное влияние оказывают режимы цементации.

Режимы цементации, проводимой перед последующей стадией технологического процесса титанирования, также оказывают существенное влияние на эксплуатационные свойства твердосплавного инструмента, имеющего диффузионные титановые покрытия. Так, в частности, было установлено значительное влияние режимов предварительной кратковременной высокотемпературной цементации на структуру диффузионных титановых покрытий. Микрофотографии твердых сплавов после цементации и диффузионного титанирования представлены на Рис. 6. 
В результате проведенных исследований, представленных на Рис. 7 a,b было установлено, что эксплуатационные свойства твердосплавного режущего инструмента, упрочненного диффузионным титанированием в среде легкоплавких жидкометаллических растворов резко, возрастают [11]. Большая толщина слоя на сплавах ВК объясняется большим содержанием кобальта, образующим с углеродом карбид $\mathrm{Co}_{2} \mathrm{C}$. Так диффузионное титанирование сплава Т15К6 обеспечивает рост поверхностной твердости до 30000 МПа, а сплава ВК8 до 25000 МПа. Большая твердость покрытий на сплавах типа ТК объясняется большей концентрацией в них карбида титана [2]. Однако эксплуатационные свойства диффузионно-титанированных твердых сплавов определяются не только твердостью и износотойкостью поверхностного слоя, но и в большинстве случаев твердостью переходного слоя под титановым покрытием, так как пониженная твердость этого слоя под действием сил резания может приводить к продавливанию и разрушению покрытия.

Как следует из анализа графиков распределения микротвердости в зависимости от расстояния от поверхности (Рис. 7), основным параметром, определяющим твердость переходного слоя, является температура предварительной цементации.

По мере увеличения температуры предварительной цементации происходит увеличение микротвердости переходного слоя под титановым покрытием. Так, например, при цементации сплава Т15К при температуре $1150^{\circ} \mathrm{C}$, микротвердость переходного слоя под титановым покрытием относительно обезуглероженного слоя (без цементации) увеличилась с 17500 до 24800 МПа, а на сплаве ВК 8 - с 15000 до 22500 МПа.

Снижение температуры цементации ниже $1150^{\circ} \mathrm{C}$ влечет за собой уменьшение микротвердости переходного слоя под титановым покрытием. При снижении

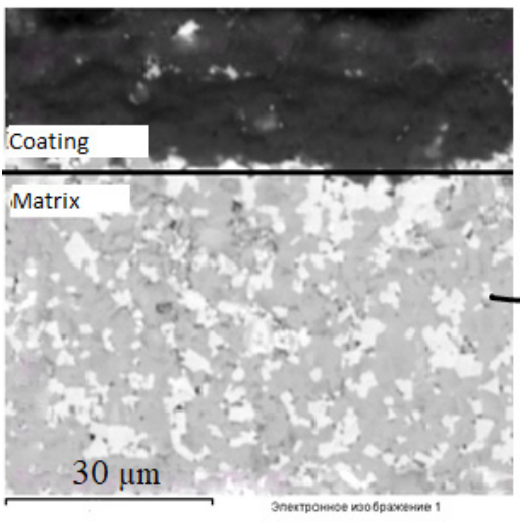

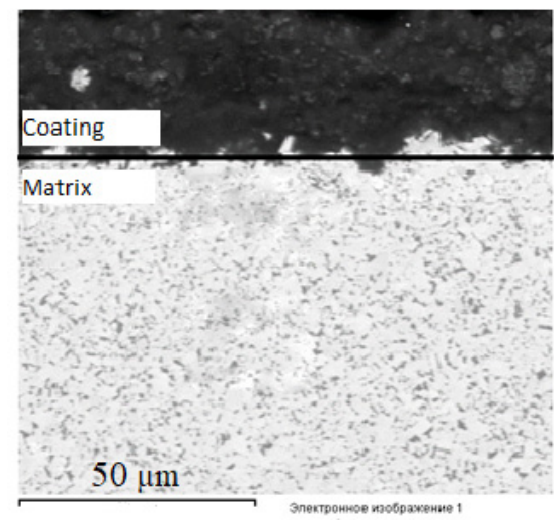

b

Рис. 6. Диффузионное титановое покрытие на твердом сплаве после проведения предварительной высокотемпературной цементации: Т15К6 (a), ВК8 (b).

Fig. 6. Diffusion titanium coating on hard alloy after previous high-temperature carburization: TiC15\%-WC79\%-Co6\% (a), WC92\%-Co8\% (b).

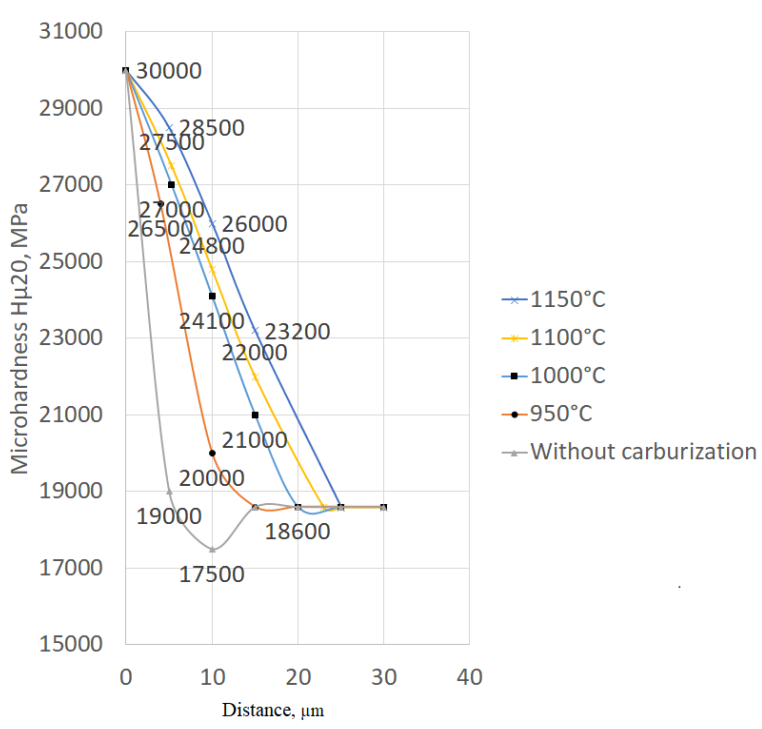

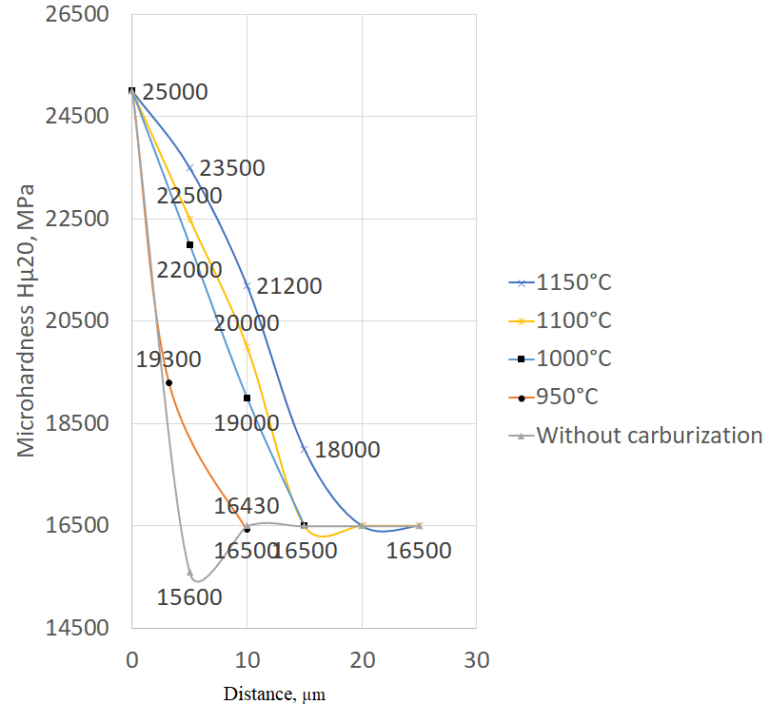

$\mathrm{b}$

Pис. 7. (Color online) Зависимость распределения микротвердости в поверхностных слоях титанированных твердых сплавов от температуры цементации: Т15К6 (a), ВК8 (b).

Fig. 7. (Color online) Depending of microhardness distribution to carburization temperature in surface layers of titan-saturated hard alloy: TiC15\%-WC79\%-Co6\% (a), WC92\%-Co8\% (b). 
температуры предварительной цементации до $1000^{\circ} \mathrm{C}$ происходит уменьшение микротвердости переходного слоя под титановым покрытием сплава Т15К6 до 22000 МПа, а на сплаве ВК8 - до 20800 МПа.

Наибольшее падение микротвердости переходного слоя под титановым покрытием наблюдается после предварительной цементации, проведенной ниже $950^{\circ} \mathrm{C}$.

Таким образом, проведение кратковременной высокотемпературной цементации является необходимой стадией технологического процесса при нанесении функциональных диффузионных титановых покрытий на твердосплавные инструменты. При этом, выбор режима предварительной цементации существенно влияет на твердость, и, как следствие, на стойкость режущего твердосплавного инструмента, имеющего титановое покрытие. С увеличением температуры и длительности предварительной цементации происходит увеличение твердости покрытия. Однако содержание большого количества углерода в покрываемом материале влечет за собой уменьшение стойкости покрытого инструмента за счет увеличения хрупкости покрытия.

\section{4. Выводы}

1. Проведение предварительной цементации ведет к образованию кобальта $\mathrm{Co}_{2} \mathrm{C}$ в поверхностных слоях твердых сплавов.

2. При нанесении износостойких диффузионных титановых покрытий на твердосплавной инструмент цементация является необходимой стадией технологического процесса. При этом, рекомендуемая температура цементации $1100^{\circ} \mathrm{C}$, длительность 90 минут.

3. Увеличение температуры цементации позволяет увеличить микротвердость поверхностногослоя твердого сплава до $30000 \mathrm{MПа} \mathrm{при} \mathrm{температуре} 1150^{\circ} \mathrm{C}$ для сплава Т15К6 и 25000 МПа при температуре $1150^{\circ} \mathrm{C}$ для сплава ВК8, и добиться исключения обезуглероживания слоя под покрытием после диффузионного титанирования. При этом чрезмерное увеличение температуры приводит к формированию хрупкого покрытия.

4. Цементация влияет на структуру и свойства как самого покрытия, так и слоя под покрытием - с увеличением температуры увеличивается микротвердость слоя под покрытием.

\section{Литература/References}

1. K. Bobzin. CIRP journal of manufacturing science and technology. 18, 1 (2017). $\underline{\text { Crossref }}$
2. A.G. Sokolov, E.E. Bobylyov. Letters on materials. 7 (3), 222 (2017). (in Russian) [А.Г. Соколов, Э.Э. Бобылёв. Письма о материалах. 7 (3), 222 (2017).] Crossref

3. A.G. Sokolov, E.E. Bobylyov. Solid State Phenomena. 256, 181 (2017). Crossref

4. R.D. Agzamov, A.F. Tagirov, K. N. Ramazanov. Defect and Diffusion Forum. 383, 161 (2018). Crossref

5. S. V. Konovalov, V.E. Kormyshev, V.E. Gromov, Y. F. Ivanov, E. V. Kapralov, A. P. Semin. Journal of Surface Investigation. 10 (5), 1119 (2016). Crossref

6. E.E. Bobylyov. Povyshenie ekspluatacionnyh svojstv rezhushchego tverdosplavnogo instrumenta za schet diffuzionnoj metallizacii iz sredy legkoplavkih zhidkometallicheskih rasplavov: Dissertacija na soiskanie stepeni doktora tehnicheskih nauk. Krasnodar. Kuban State Technological Univercity, Krasnodar (2019)180 p. (in Russian) [Э.Э. Бобылёв. Повышение эксплуатационных свойств режущего твердосплавного инструмента за счет диффузионной металлизации из среды легкоплавких жидкометаллических расплавов: дис. кан-та техн. наук. Краснодар (2019)180 с.]

7. V.P. Artem'ev, M.I. Chaevsky. Adhesion of melts and soldering of materials. 16, 82 (1986). (in Russian) [В.П. Артемьев, М.И. Чаевский. Адгезия расплавов и пайка материалов. 16, 82 (1986).]

8. Y.F. Ivanov, N. N. Koval, S. V. Gorbunov, S. V. Vorobyov, S. V. Konovalov, V.E. Gromov. Russian Physics Journal. 54 (5), 575 (2011). Crossref

9. A.G. Sokolov. Development of theoretical and technological bases for increasing the resistance of cutting and stamping tools due to diffusion metallization from the medium of low-melting liquid metal solutions. Dissertacija na soiskanie stepeni doktora tehnicheskih nauk. Krasnodar (2008) 369 p. (in Russian) [А. Г. Соколов Разработка теоретических и технологических основ повышения стойкости режущего и штампового инструмента за счет диффузионной металлизации из среды легкоплавких жидкометаллических растворов: Дис. д-ра техн.наук. Краснодар (2008) 369 с.]

10. Diagrammy sostoyaniya dvojnyh metallicheskih sistem: Spravochnik: v 3 T (ed. by N.P. Lyakishev). Moscow, Mashinostroenie (1996) 992 p. (in Russian) [Диаграммы состояния двойных металлических систем: Справочник: в 3 Т. (под общ. ред. Н.П. Лякишева). Москва, Машиностроение (1996) 992 с.]

11. E. E. Bobylyov. Journal of Physics: Conference Series. 1399, 44085 (2019). Crossref 